\title{
Historical Aspects and Surgical Nuances on the Craniocervical Approach to the Jugular Foramen
}

\section{Aspectos históricos e dicas do acesso craniocervical ao forame jugular}

\author{
Felipe Constanzo ${ }^{1,2}$ () \\ Gustavo Fabiano Nogueira ${ }^{3}$ \\ ${ }^{1}$ Department of Skull Base Surgery, Clinica Bio Bio, Concepción, Chile \\ ${ }^{2}$ Department of Neurological Surgery, Hospital Clinico Regional de \\ Concepción, Concepción, Chile \\ ${ }^{3}$ Department of Otolaryngology, Instituto de Nuerologia de Curitiba, \\ Curitiba, PR, Brazil \\ ${ }^{4}$ Department of Neurosurgery, Instituto de Neurologia de Curitiba, \\ Curitiba, PR, Brazil
}

Arq Bras Neurocir 2022;41(2):e174-e179.
Mauricio Coelho Neto ${ }^{4}$ Ricardo Ramina 4 ()

\author{
Address for correspondence Felipe Constanzo, MD, Department of \\ Skull Base Surgery, Clinica Bio Bio Avenida Alessandri 3515, \\ Talcahuano, Chile (e-mail: constanzo.md@gmail.com).
}

\begin{abstract}
Keywords

- jugular foramen

- schwannoma

- meningioma

- paraganglioma

- skull base neoplasms

Context Tumors of the jugular foramen present a challenge to skull base surgeons. Their rarity, coupled with the complex anatomy of the region require exquisite knowledge and surgical technique. We present the history of the craniocervical approach to the jugular foramen, as well as surgical advice on how to manage the different extensions these tumors may present. The surgical nuances come from the experience of our skull base team managing over 150 tumors of the jugular foramen over the past 30 years. The history of the craniocervical approach was obtained by reviewing articles on surgery of the jugular foramen published on PUBMED over the past 100 years.

History The first craniocervical approach may be attributed to Gardner et al. in 1891, with posterior contributions from Shapiro and Neues, Gejrot, Kempe et al, Hilding and Greenberg, and Glasscock.

Nuances Cervical dissection with identification of the jugular vein, carotid bifurcation, and IX to XII cranial nerves was performed. Mastoidectomy with exposition of the fallopian canal, labyrinth, middle ear, sigmoid sinus, followed by a trans-sigmoid craniotomy with transposition of the vertebral artery gave access to the temporal and intracranial region.

Conclusion Approaching the jugular foramen is the epitome of skull base surgery. Several modifications of the standard approach may be necessary depending on the extension of the tumor.
\end{abstract}

received

January 20, 2021

accepted

April 16, 2016

published online

January 31, 2022
DOI https://doi.org/ 10.1055/s-0041-1739166. ISSN 0103-5355.

\footnotetext{
(c) 2022. Sociedade Brasileira de Neurocirurgia. All rights reserved. This is an open access article published by Thieme under the terms of the Creative Commons Attribution-NonDerivative-NonCommercial-License, permitting copying and reproduction so long as the original work is given appropriate credit. Contents may not be used for commercial purposes, or adapted, remixed, transformed or built upon. (https://creativecommons.org/ licenses/by-nc-nd/4.0/) Thieme Revinter Publicações Ltda., Rua do Matoso 170, Rio de Janeiro, RJ, CEP 20270-135, Brazil
} 


\section{Resumo}

\section{Palavras-chave \\ - forame jugular \\ - schwannoma \\ - meningioma \\ - paraganglioma \\ - base do crânio}

Contexto Os tumores do forame jugular apresentam um desafio para os cirurgiões da base do crânio. A sua raridade e a anatomia complexa da região requerem conhecimento específico da técnica cirúrgica. O presente manuscrito apresenta a história do acesso crâniocervical ao forame jugular, assim como dicas cirúrgicas para manejar as diferentes extensões que os tumores podem apresentar. As dicas são derivadas da experiência da nossa equipe em mais de 150 tumores do forame jugular nos últimos 30 anos. A história do acesso crâniocervical foi obtida da revisão de artigos em PUBMED dos últimos 100 anos.

História A primeira abordagem craniocervical pode ser atribuída a Gardner et al. em 1891, com contribuições posteriores de Shapiro e Neues, Gejrot, Kempe et al, Hilding e Greenberg e Glasscock.

Descrição A dissecção cervical necessita identificação da veia jugular, bifurcação carotídea, e dos nervos cranianos de IX a XII. A mastoidectomia com exposição do canal de falópio, labirinto, ouvido médio e seio sigmoide foi seguida por uma craniotomia transsigmoide com transposição da artéria vertebral, permitindo abordar a região temporal e intracraniana.

Conclusão Acessar o forame jugular é o epítome da cirurgia da base do crânio. Múltiplas modificações do acesso tradicional podem ser necessárias dependendo da extensão do tumor.

\section{Context}

Tumors of the jugular foramen have been a challenge to diagnose, define its origin, classify and treat. For the past century, otolaryngologists and neurosurgeons have transformed management of tumors in this region, achieving high rates of gross total resection and low rates of neurological deficits and death. ${ }^{1}$ Due to their rarity, the learning curve for approaching the jugular foramen is particularly steep, probably steeper than for any other region of the body, therefore centering their management in a few high-volume centers. There is a myriad of approaches to the jugular foramen, ${ }^{2}$ each with specific indications and complications, and due to their complexity, it may not be possible to become proficient in all of them, which is why we advocate the use of the same approach whenever possible. Of all the described approaches, we believe the craniocervical approach is the most versatile, allowing exposure of the cervical, mastoid, and intracranial regions, thus, being the most suitable for skull base groups to rely on. In the following text, we present the history of the craniocervical approach, and the different variants that may be performed according to the particular characteristics of the lesion to be resected.

\section{Evidence Acquisition}

We reviewed the PUBMED database to identify articles describing surgical techniques for the jugular region. The surgical nuances are derived from our experience with more than 150 tumors of the jugular foramen treated over the past 33 years by the skull base team of the Neurological Institute of Curitiba, Brazil. The present manuscript was approved by the institutional review board of our center.

\section{Results}

\section{Tumors of the Jugular Foramen}

Tumors of the jugular foramen may be broadly classified into primary lesions, arising from within the jugular foramen, such as paragangliomas, schwannomas, meningiomas, and aneurysmal bone cysts, as well as into lesions with secondary extension into the jugular foramen, such as chondrosarcomas, chordomas, cholesteatomas, and meningiomas of the cerebellopontine angle that grow into the jugular foramen. ${ }^{3}$ Paragangliomas are by far the most frequent, followed by schwannomas, and, then, meningiomas. ${ }^{4}$ In the present article, we will focus on the surgical nuances for primary lesions, as they represent the basic concepts and details that may be extrapolated to secondary tumors.

\section{History of the Craniocervical Approach}

The history of the surgery of the jugular foramen has been exquisitely detailed in previous publications. ${ }^{1}$ Since most tumors present with ear symptoms, early literature was dominated by otolaryngologists, with the first reports of neurosurgical exploration for jugular tumors arising in $1951,5,6$ and a further report of a glomic tumor arising from the jugular foramen successfully resected through a suboccipital approach in the same year. ${ }^{7}$ The description of the craniocervical approach as such may be attributed to Shapiro and Neues in $1864^{8}$ and Gejrot in $1965 .^{9}$ They described the cervical resection, radical mastoidectomy and transposition of the facial nerve, but they did not dare entering the posterior fossa, leaving intracranial tumors for radiation therapy. In the 70s, with the advent of skull base teams composed of neurosurgeons, otolaryngologists, and head and neck surgeons, tumors of the jugular foramen were 

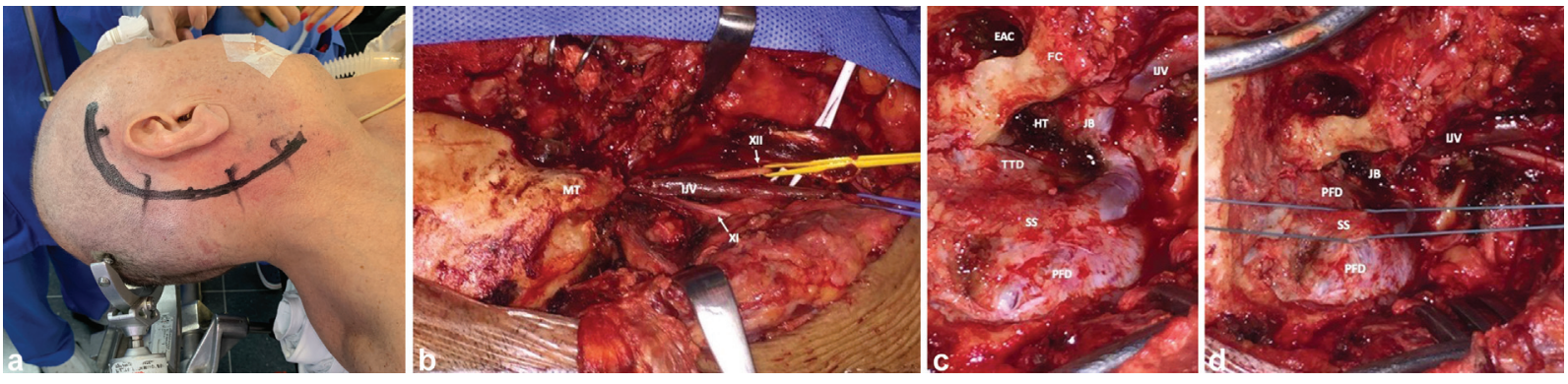

Fig. 1 Steps of a classic right craniocervical approach. (a) Head positioning and skin incision, beginning above the pinna and extending into the cervical region. (b) Neck dissection, identifying the internal jugular vein (IJV), hypoglossal nerve (XII), accessory nerve (XI), and mastoid tip (MT). (c) Mastoidectomy and craniectomy, with exposure of the posterior fossa duramater (PFD), sigmoid sinus (SS), jugular bulb (JB), IJV, hypotympanum (HT), external auditory canal (EAC), Treutmann triangle duramater (TTD), and fallopian canal (FC). (d) Ligature of the sigmoid sinus. The superior petrosal nerve is not exposed during the approach.

now thought of as neurosurgical, otological, and cervical problems. ${ }^{10}$ In 1971 , Kempe et al. ${ }^{11}$ performed a suboccipital craniotomy and mastoidectomy to resect a glomus jugulare tumor of the middle ear and intracranial compartment. They also described the ligation of the sigmoid sinus and jugular vein, with resection of the tumor inside the jugular bulb. In the same year, Hilding \& Greenberg ${ }^{12}$ reported a similar approach that included exposure of the internal carotid artery through the glenoid fossa and packing of the inferior petrosal sinus after resection of the tumor. In 1974, Glasscock et al. ${ }^{13}$ proposed a protocol for the diagnosis and treatment that described the use of the extended facial recess to remove tumor from the hypotympanum without transposing the facial nerve, and reconstruction of the tympanic membrane when the external auditory canal was exposed (both techniques had been previously described, but not for glomus jugulare tumors). Finally, Gardner et al. ${ }^{14}$ published their series of combined cervical, temporal, and intracranial resection of glomus jugulare tumors in 1981, and then, Al-Mefty et al. ${ }^{15}$ reported its use for large tumors in 1987. Afterwards, several authors have added small changes to the approach, according to particular extensions, which we will further discuss below.

\section{The Modern Craniocervical Approach}

The craniocervical approach has been described at length in previous articles. ${ }^{1}$ Briefly, a complete approach consists of a C-shaped incision extending from the temporal region to the cervical region anterior to the sternocleidomastoid muscle ( - Fig. 1a). Dissection of the neck consists of identification of the cervical tumor, cranial nerves IX to XII, carotid artery, jugular vein, and vertebral artery (-Fig. 1b). Then, a mastoidectomy is performed to expose the jugular foramen and sigmoid sinus, labyrinth, middle ear, and fallopian canal. A small craniectomy fully exposing the sigmoid sinus with transposition of the vertebral artery is also performed. (-Fig. 1c) After complete exposition of the region, the jugular vein and sigmoid sinus are ligated, and the tumor is removed en bloc from the temporal and cervical areas. The duramater medial to the sigmoid sinus is opened afterwards to resect the intracranial tumor, and, after hemostasis, the skull base is reconstructed.

\section{Rationale for Using the Craniocervical Approach}

As previously stated, the rarity of tumors of the jugular foramen limits the exposure skull base surgeons have to different approaches, so we must rely on a few of them that allow us to solve most problems and develop an adequate learning curve. Here, the craniocervical approach is unmatched, giving access to all the compartments the tumor may grow into; therefore, it may be tailored to each particular case. After incision and exposure of the craniocervical region and neck dissection, mastoidectomy and craniotomy are performed according to extension of the tumor into each compartment. ( - Fig. 2a).

The first tailoring may be performed according to the histology of the tumor. A paraganglioma almost always
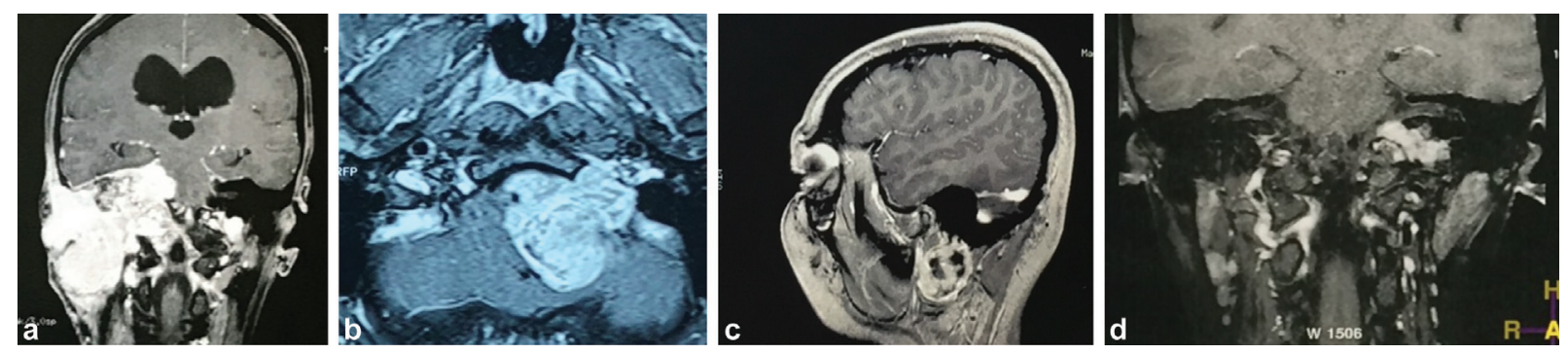

Fig. 2 Several extensions of jugular foramen tumors. (a) Giant right glomus jugulare tumor, occupying the entire mastoid bone and extending intracranially and into the cervical and retropharyngeal space. (b) Left jugular foramen schwannoma from the cerebellopontine angle with limited extension into the jugular foramen by the glossopharyngeal canal. (c) Vagal schwannoma of the cervical region, extending up into the skull base, but without entering the jugular foramen. (d) glomus tympanicum extending into the hypotympanum, below the internal auditory canal. 
grows into the venous system, so regardless of the compartment it occupies, the cranial and caudal poles of the tumor inside the jugular vein and sigmoid sinus must be exposed. Schwannomas, on the other hand, usually grow medial to the jugular bulb and vein, needing greater anterior exposure but usually without needing to sacrifice the venous system. Meningiomas are probably the most difficult to completely resect, given their extension into the internal auditory canal, fallopian canal, middle fossa, infratemporal fossa, and paranasal sinuses, ${ }^{16}$ with frequent invasion of the sigmoid sinus and jugular bulb, thus needing to be removed. The craniocervical approach does allow for complete resection; however, reconstruction of the skull base must be thoroughly planned beforehand.

Perhaps the only exception for the use of the craniocervical approach is when a tumor is located mostly in the intracranial compartment and less than $1 \mathrm{~cm}$ within the jugular foramen (-Fig. 2b), in which case a retrosigmoid infralabyrinthine (suprajugular) approach may be suitable for some lesions, ${ }^{17,18}$ though the principles stated above must be considered. This makes schwannomas and meningiomas ideal for a suprajugular approach, whereas paragangliomas and chordomas/chondrosarcomas usually need more extensive bone resection.

\section{Technical Nuances}

\section{Cervical Extension}

This is the most variable part of the approach, and the cervical extension of the incision is tailored to the tumor extension on preoperative imaging. In most cases, identification of the bifurcation of the carotid artery is usually necessary to have proximal arterial control in case of bleeding. Using the carotid bifurcation is a good landmark to properly expose the inferior pole of a paraganglioma inside the jugular vein, as well as to identify the cranial nerves IX to XII in the upper cervical region and avoid unintended traction of the IX and X nerves during dissection. In cases in which the tumor does not invade the venous system nor extends into the cervical region, we advocate for a limited upper cervical dissection, so as to expose the extracranial jugular foramen and to provide an adequate angle of attack to the mastoid region.

\section{Management of Vascular and Nervous Structures}

Before the advent of endovascular embolization, the external carotid artery was often ligated in paragangliomas and meningiomas, given that their primary arterial supply comes from the ascending pharyngeal and occipital arteries. Nowadays, both the internal and external carotid arteries are usually left in place, and the bifurcation is used to identify the hypoglossal nerve travelling $2 \mathrm{~cm}$ cranial to it. In rare cases, the internal carotid artery may be eroded by the tumor, and, in those cases, the use of an extracranial-to-intracranial bypass must be considered before resection. Management of the jugular vein depends mostly on the histology of the tumor. For schwannomas, the venous system is usually displaced by the tumor, and, therefore, there is no need to sacrifice it. In some meningiomas and all paragangliomas, the venous system is compromised, and the jugular vein must be resected en bloc with the tumor. For that matter, the jugular vein must be completely freed from the adjacent carotid artery and vagus nerve (passing between them), and then ligated below the inferior pole of the tumor. Of note, the accessory nerve follows a posteroinferior course after leaving the jugular foramen, crossing the jugular vein in its anterolateral surface, and must be carefully preserved when performing en bloc resection (-Fig. 1b). In case of schwannomas, differentiation of the origin from the glossopharyngeal or vagus nerve is of uttermost importance when the tumor presents cervical extension, since a glossopharyngeal schwannoma will be located medial and anterior to the carotid artery, displacing it posteriorly, whereas a vagal paraganglioma will be located between the carotid and jugular vein, displacing the carotid anterior and medial, and the jugular vein posterior and lateral. Finally, the craniocervical approach exposes the greater auricular nerve during superficial (suprafascial) dissection. The nerve must be preserved and dissected throughout its cervical course to avoid auricular hypesthesia or paresthesia, and, eventually, it can also be used as a cable graft if needed, though sural grafts are preferred.

\section{Temporal Extension}

Mastoidectomy is the most crucial part of the approach, and several modifications may be needed according to the extension of the tumor. The basic mastoidectomy includes drilling of air cells until identification of the bony labyrinth, identification of the fallopian canal, opening of the mastoid antrum, exposition of the duramater of the Treutmann triangle, skeletonization of the jugular bulb and sigmoid sinus up to the sinodural angle, and removal of the mastoid tip (-Fig. 1c). In selected cases in which a mainly cervical tumor only occupies the inferior pole of the petrous bone and there is no invasion of the venous system ( $\mathbf{F i g . 2 c}$ ), a limited mastoidectomy with resection of the mastoid tip may be performed.

\section{Extension into Hypotympanum and Facial Nerve Transposition}

Particularly in paragangliomas extending through the tympanic plexus ( $\mathbf{- F i g . ~ 2 d ) , ~ t h e ~ s k i n ~ o f ~ t h e ~ e x t e r n a l ~ a u d i t o r y ~}$ canal may be peeled off the tympanic bone, the tympanum detached from its posterior insertion, and the posterior wall of the external auditory canal drilled down to get the tumor through the facial recess, without opening the fallopian canal (-Fig. 1c). Nowadays, the only indication to expose and reroute the facial nerve is when the tumor itself invades the canal/nerve, such as in some meningiomas or paragangliomas, though it is the exception.

\section{Management of Inner and Middle Ear Structures}

Due to earlier diagnosis, tumors of the jugular foramen usually present with normal hearing, making hearing preservation a goal of surgery. A retrolabyrinthine mastoidectomy is sufficient to approach tumors of the jugular foramen, 


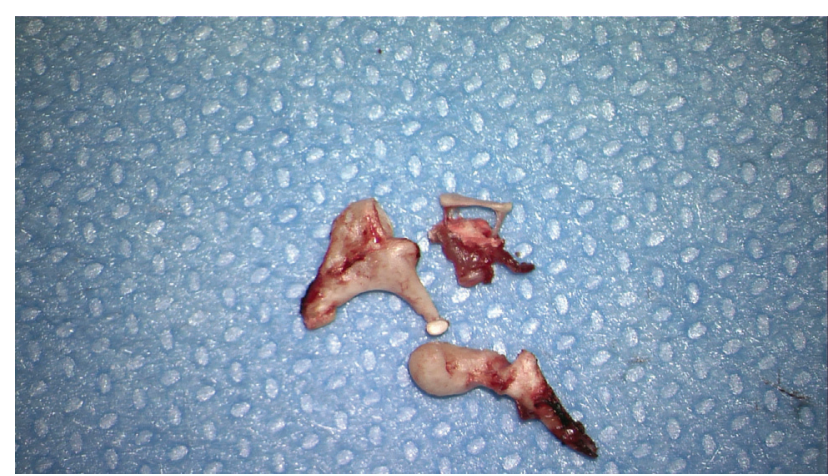

Fig. 3 Auditory ossicles from a patient with a glomus jugulare tumor and preserved hearing. Resection of the ossicles was necessary due to invasion of the stapes by tumor.

since their intracranial extension is removed via trans-sigmoid craniotomy, avoiding the need of a transcrural/translabyrinthine extension. The middle ear, however, needs to be exposed during the approach, especially because the short process of the incus is an important landmark to identify the tympanic segment of the facial nerve. Special care must be taken to avoid disarticulating the ossicles when hearing preservation surgery is attempted; however, if the tumor invades the middle ear (even with preserved hearing), the ossicles are frequently compromised and must be resected (-Fig. 3 ). In cases in which the tympanum has to be detached, tympanoplasty with temporal fascia ${ }^{19}$ must be attempted to preserve conduction. In cases in which hearing was already compromised, the external auditory canal may be closed, or, most frequently, left open to the mastoid cavity, which allows for postoperative endoscopic evaluation of the surgical site.

\section{Management of Vascular and Nervous Structures}

In the temporal bone, early identification of the facial nerve is paramount. The tympanic segment of the facial nerve lays $1.5 \mathrm{~cm}$ medial to the spine of Henle, between the short process of the incus and lateral semicircular canal. At the level of the stylomastoid foramen, the nerve is identified by the tarsal "pointer." After removing the mastoid tip, the mastoid segment of the facial nerve may be delineated by joining both reference points in the anterior mastoid. In the jugular foramen, it is important to remember that nerves run medial to the jugular bulb, so paragangliomas will most likely displace bulbar nerves medially, whereas schwannomas will displace the jugular bulb laterally. Moreover, the glossopharyngeal nerve passes through its own canal, located more anterior and superior to the vagal and accessory nerves, and it is separated by a dural fold. All these anatomical details are extremely important to foresee the location of those structures in order to preserve them. In the same way, the carotid artery is located inside the carotid canal, anteromedial to the jugular foramen, and though it is not usually exposed, a dehiscent canal may be encountered, the tumor may erode into the carotid artery, or in case of paragangliomas and meningiomas, they may be fed by caroticotympanic branches arising from the petrous carotid artery, so preoperative images must be evaluated for these possibilities. Finally, in cases in which the venous system must be sacrificed, the sigmoid sinus must be ligated below the sinodural angle so as to preserve circulation between the transverse and superior petrous sinuses (-Fig. 1d). After en bloc resection of the tumor, brisk bleeding is expected from the inferior petrous sinus, which can be stopped with packing with oxidized cellulose.

\section{Intracranial Extension}

A limited, 3-cm craniectomy anterior and posterior to the sigmoid sinus is usually sufficient to approach an intradural tumor. Since the jugular foramen lays in the inferior part of the posterior fossa, transposition of the vertebral artery from the vertebral sulcus of $\mathrm{C} 1$ (and partial resection of the transverse process of $\mathrm{C} 1$ ) provides ample space to work in the lateral cerebellomedullary cistern. We perform this transposition in most cases when there is intracranial extension of the tumor, and we consider leaving the vertebral artery in place only when the intracranial extension is small, particularly in schwannomas.

\section{Management of Vascular and Nervous Structures}

In the lateral cerebellomedullary cistern, the same relationship between bulbar nerves and the jugular bulb is encountered. The microsurgical technique for separating the tumor from the nerves depends on the histology of the lesion. Meningiomas and paragangliomas are adherent to the surrounding nerves, whereas schwannomas are more easily dissected (except for the nerve it originates from). If the bulbar cranial nerves are infiltrated, and the patient presents previously deficits, radical tumor removal with the infiltrated nerves is performed. Damage of these nerves should be avoided if their function has not been already compromised by the tumor. The intradural vertebral artery and branches are not usually compromised, but, rarely, they may feed the tumor (-Fig. 4).

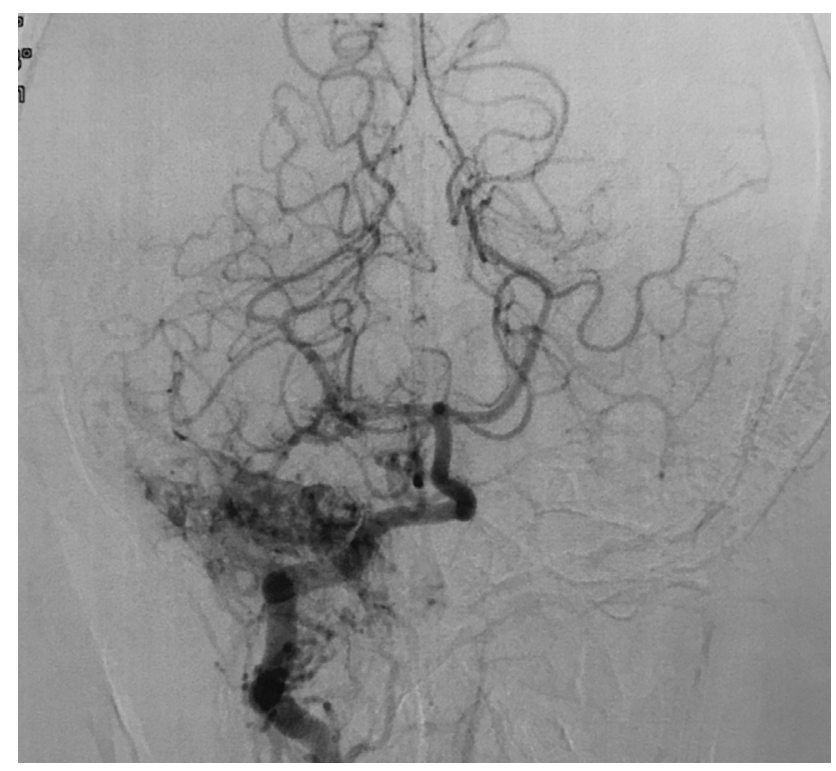

Fig. 4 Right vertebral digital subtraction angiography showing filling of a glomus jugulare tumor by fine branches of the V3 (atlantic) and V4 (intradural) segments of the vertebral artery. 


\section{Closure and Postoperative Care}

Closing the surgical defect must be planned preoperatively. We advocate for the use of a multilayered closure with pedicled flaps in lieu of avascular fat grafts. Our group has previously published a technique using temporo-cervical fascia anchored in the sternocleidomastoid muscle, and temporal and digastric muscles to avoid cerebrospinal fluid leaks and achieve good cosmetic outcomes. ${ }^{20}$

After surgery, the decision to extubate depends on the degree of manipulation of bulbar nerves during surgery. Most cases are extubated immediately after surgery, when irritation of the cranial nerves was minimal according to intraoperative monitoring readings. When in doubt, it is appropriate to wait until the patient is fully awake to ensure that the airway is sustained before removing the tube. All patients benefit from early phonoaudiological evaluation to assess pharyngeal function and begin early oral feeding, if possible.

\section{Conclusion}

Approaching the jugular foramen is the epitome of skull base surgery. Extensive exposure by means of bone removal with minimal manipulation of neural tissue, based on anatomical knowledge, allows for total resection with minimal morbidity. Variable extension of tumors in this region warrants small but significant modifications to the standard approach.

\section{Conflict of Interests}

The authors have no conflict of interests to declare.

\section{References}

1 Ramina R, Tatagiba MS, Eds. Tumors of the Jugular Foramen. Switzerland: Springer; 2017

2 Komune N, Matsushima K, Matsushima T, Komune S, Rhoton AL Jr. Surgical approaches to jugular foramen schwannomas: An anatomic study. Head Neck 2016;38(Suppl 1):E1041-E1053

3 Ramina R, Maniglia JJ, Fernandes YB, Paschoal JR, Pfeilsticker LN, Coelho Neto M. Tumors of the jugular foramen: diagnosis and management. Neurosurgery 2005;57(1, Suppl)59-68, discussion $59-68$
4 Ramina R, Maniglia JJ, Fernandes YB, et al. Jugular foramen tumors: diagnosis and treatment. Neurosurg Focus 2004;17(02):E5

5 Dockerty MB, Love JG, Patton MM. Nonchromaffin paraganglioma of the middle ear; report of a case in which the clinical aspects were those of a brain tumor. Proc Staff Meet Mayo Clin 1951;26 (02):25-32

6 Poppen JL, Riemenschneider PA. Tumor of carotid body type presumably arising from the glomus jugularis. AMA Arch Otolaryngol 1951;53(04):453-459

7 Alexander E Jr, Beamer PR, Williams JO. Tumor of the glomus jugulare with extension into the middle ear; nonchromaffin paraganglioma or carotid-body-type tumor. J Neurosurg 1951;8 (05):515-523

8 Shapiro MJ, Neues DK. Technique for Removal of Glomus Jugulare Tumors. Arch Otolaryngol 1964;79:219-224

9 Gejrot T. Surgical treatment of glomus jugulare tumours with special reference to the diagnostic value of retrograde jugularography. Acta Otolaryngol 1965;60:150-168

10 Portmann M, Hamberger CA, Wersäll J, editors. Disorders of the Skull Base Region. New York: John Wiley \& Sons Inc.; 1969; p288

11 Kempe LG, VanderArk GD, Smith DR. The neurosurgical treatment of glomus jugulare tumors. J Neurosurg 1971;35(01):59-64

12 Hilding DA, Greenberg A. Surgery for large glomus jugulare tumor. The combined suboccipital, transtemporal approach. Arch Otolaryngol 1971;93(03):227-231

13 Glasscock ME III, Harris PF, Newsome G. Glomus tumors: diagnosis and treatment. Laryngoscope 1974;84(11):2006-2032

14 Gardner G, Cocke EW Jr, Robertson JT, Trumbull ML, Palmer RE. Glomus jugulare tumours-combined treatment: part II. J Laryngol Otol 1981;95(06):567-580

15 Al-Mefty O, Fox JL, Rifai A, Smith RR. A combined infratemporal and posterior fossa approach for the removal of giant glomus tumors and chondrosarcomas. Surg Neurol 1987;28(06):423-431

16 Ramina R, Neto MC, Fernandes YB, Aguiar PHP, de Meneses MS, Torres LFB. Meningiomas of the jugular foramen. Neurosurg Rev 2006;29(01):55-60

17 Samii M, Tatagiba M. Tumors of the Jugular Foramen. Neurosurgery Quarterly 1996;6(03):176-193

18 Constanzo F, Gerhardt J, Ramina R. How I do it: retrosigmoid suprajugular approach to the jugular foramen. Acta Neurochir (Wien) 2019;161(11):2271-2274

19 Glasscock ME III. Tympanic membrane grafting with fascia: overlay vs. undersurface technique. Laryngoscope 1973;83(05):754-770

20 Ramina R, Maniglia JJ, Paschoal JR, Fernandes YB, Neto MC, Honorato DC. Reconstruction of the cranial base in surgery for jugular foramen tumors. Neurosurgery 2005;56(2, Suppl)337-343 , discussion 337-343 